\title{
Maternal Exercise Activates Genes Associated with Mitochondrial Biogenesis in Fetal Myocardium of Mouse
}

HAYLI E. JOINER, TRACER SKELTON, KALLI D. LOOTEN, and EUNHEE CHUNG
Molecular Exercise Physiology; Department of Kinesiology and Sport Management; Texas Tech University; Lubbock, TX

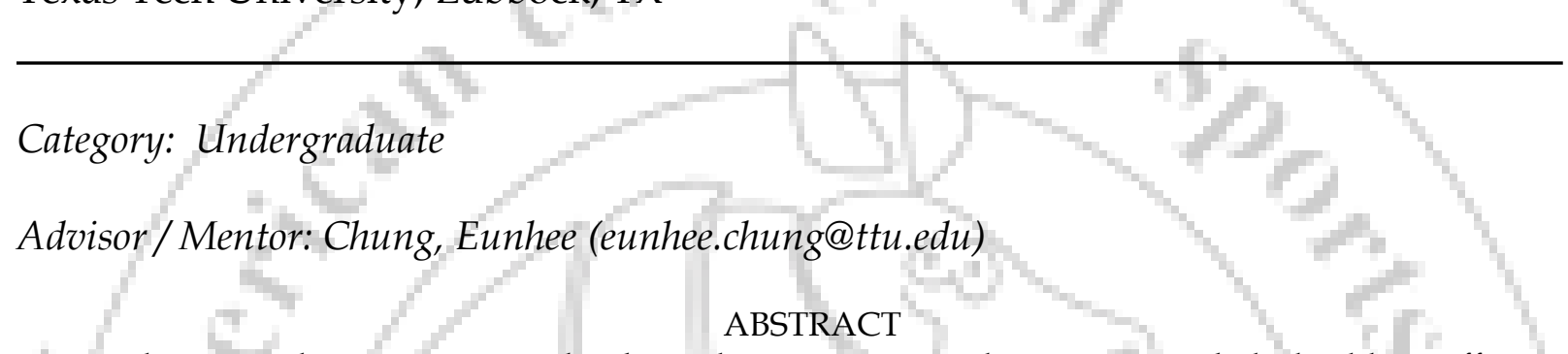

Maternal exercise during pregnancy has been shown to improve long-term metabolic health on offspring in later life. Mitochondria are the critical site of metabolism, and are inherited by maternal origin. However, the effects of maternal exercise during pregnancy on fetal mitochondrial biogenesis are not well understood. PURPOSE: To test whether maternal exercise can activate genes associate with mitochondrial biogenesis in the fetal heart. METHODS: Female C57BL/ 6 mice were divided into sedentary and exercise groups. The mice in the exercise group were exposed to voluntary cage-wheel from gestational day 1 through 17, at which time they were sacrificed. Litter size and individual fetal weights (3 days before birth) were taken when pregnant dams were sacrificed. All fetuses were sexed and two to three hearts from same sex within the group were pooled to study gene expression: all data were presented by group since there was no sex difference within group. RESULTS: Exercise dams ran an average of 7.22 \pm $0.41 \mathrm{~km} /$ day until mid-pregnancy and gradually decreased to low levels $(1.39 \pm 0.43 \mathrm{~km} /$ day $)$ through the remainder of gestation. Weight gain during pregnancy was not significantly different between exercise $(14.45 \pm 0.99 \mathrm{~g})$ and sedentary $(15.99 \pm 1.13 \mathrm{~g})$ pregnant dams. There were no significant differences in litter size, sex distribution, and average fetal body weight per litter between sedentary and exercise dams. Genes associated with mitochondrial biogenesis, including Ppargc1a (peroxisome proliferator-activated receptor gamma, coactivator 1 alpha), Nrf1 (nuclear respiratory factor-1), and Nrf2 (nuclear respiratory factor-2) were significantly upregulated in fetuses from exercise dams. CONCLUSION: Although total kilometers run per day ( $\mathrm{km} /$ day) were significantly decreased in later stage of pregnancy, maternal exercise initiated at day 1 of gestation significantly increased genes associated with mitochondria biogenesis, indicating that maternal exercise enhances mitochondrial biogenesis and mitochondrial function.

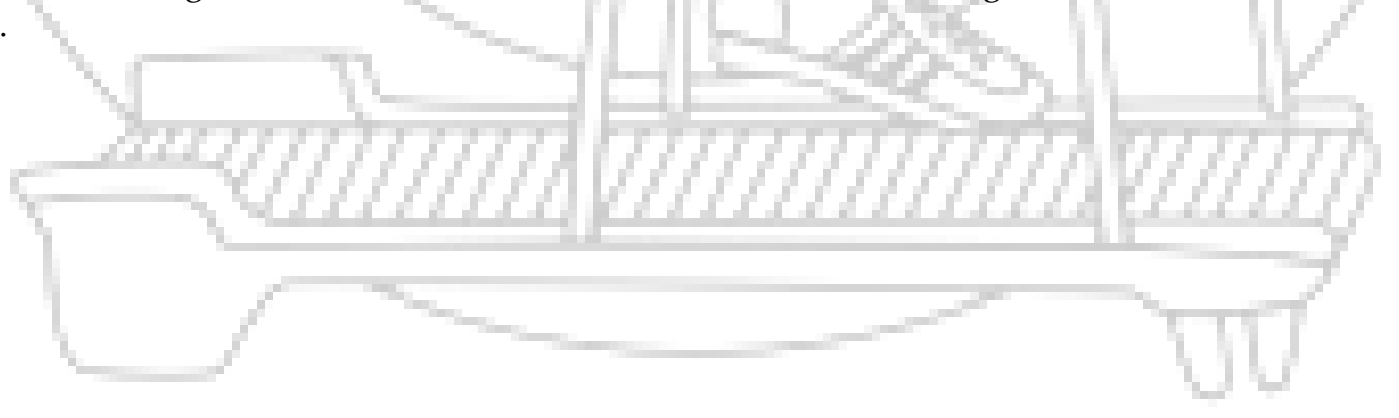

